\title{
Numerical Simulation of Liquefaction Deformation of Sand Layer around Bucket Foundations under Dynamic Loadings
}

\author{
Chi $\mathrm{Li}^{1, *}$, Xiaobing $\mathrm{Lu}^{2}$ and Shuyun Wang ${ }^{2}$ \\ ${ }^{1}$ Inner Mongolia University of Technology, Huhhot, 010051, China \\ ${ }^{2}$ Institute of Mechanics, Chinese Academy of Sciences, Beijing, 100190, China
}

\begin{abstract}
The liquefaction deformation of sand layer around a bucket foundation is simulated under equivalent dynamic ice-induced loadings. A simplified numerical model is presented by taking the bucket-soil interaction into consideration. The development of vertical and horizontal liquefaction deformations are computed under equivalent dynamic ice-induced loadings. Firstly, the numerical model and results are proved to be reliable by comparing them with the centrifuge testing results. Secondly, the factors and the development characteristics of liquefaction deformation are analyzed. Finally, the following numerical simulation results are obtained: the liquefaction deformation of sand layer increases with the increase of loading amplitude and with the decrease of loading frequency and sand skeleton's strength. The maximum vertical deformation is located on the sand layer surface and 1/4 times of the bucket's height apart from the bucket's side wall (loading boundary). The maximum horizontal deformation occurs at the loading boundary. When the dynamic loadings is applied for more than 5 hours, the vertical deformation on the sand layer surface reaches 3 times that at the bottom, and the horizontal deformation at 2.0 times of the bucket height apart from the loading boundary is $3.3 \%$ of which on the loading boundary.
\end{abstract}

Keywords: Bucket foundation, equivalent dynamic ice-induced loadings, liquefaction deformation.

\section{INTRODUCTION}

Bucket foundation is a new style offshore platform foundation and has been increasingly used in offshore engineering in recent years. Bucket foundation is often inserted into soil layer and provides the support for the platform. But the dynamic loadings, such as wave loading and ice-induced loading in ocean environment, usually cause the soil layer to liquefy and form large deformation, and thus lead the bucket foundation to lose its stability. Recently, the large liquefaction deformation and side-flow induced by sand liquefaction of sand has become a focus. Moreover, the large liquefaction deformation of soil is the main factor that makes the bucket foundation damage $[1,2]$. Some cases about the influence of the large liquefaction deformation have been reported based on lots of site investigation. Shamoto [3] and Zhang et al. [4, 5] proposed the post-liquefaction constitutive model. Liu and Gao et al. [6-8] analyzed the effects of the side-deformation of ground after seismic liquefaction on the pile foundation. However, the centrifuge experimental results show that the liquefaction of sand around bucket foundation under iceinduced dynamic loadings is different from that under the earthquake loadings. Therefore, the study on liquefaction deformation of sand around bucket foundation under iceinduced dynamic loadings is very important in both theory and practice aspects.

Considering the environmental conditions in Bohai Bay, China, the ice-induced dynamic loading is thought as the

* Address correspondence to this author at Inner Mongolia University of Technology, Huhhot, 010051,China; Tel: 86-0471-6576543; Fax: 86-04716575700; Email: tjdxlch2003@126.com main controlling load. So dynamic centrifugal experiments under ice-induced dynamic loadings are carried out in order to estimate the liquefaction and soften characteristics of sand layer surrounding the bucket foundation by $\mathrm{Lu}$ et al. [9-11]. Experimental results show that the liquefaction of sand surrounding the bucket foundation happens in local zone but not in whole zone and the development process of the liquefaction is gradual. If a part of sand layer becomes liquefaction, its shear strength will depress rapidly, and the stresses in neighboring zones will redistributed under the dynamic loadings. Subsequently, more and more sand will be liquefied and the liquefaction zone will become larger and larger. Finally, the deformation will be so large that the foundation will lose its stability or even be failure.

In this paper, a simplified calculation model of bucketsoil interaction is firstly presented based on the dynamic centrifugal experiment results. Then the diffusion rules of the sand liquefaction deformation surrounding the bucket foundation under dynamic loadings are studied by numerical simulation. Finally, the factors that lead sand layer to form liquefaction deformations are summarized in order to provide theoretical basis for the design of bucket-foundation in ocean engineering.

\section{SIMPLIFIED NUMERICAL MODEL OF BUCKET- SOIL INTERACTION}

\section{A Simplified Numerical Model}

The former numerical simulation on the bucketfoundation's bearing capacity is mainly based on three or two dimensional models by considering the interaction between the bucket and the soil layer. Also, the interaction is 


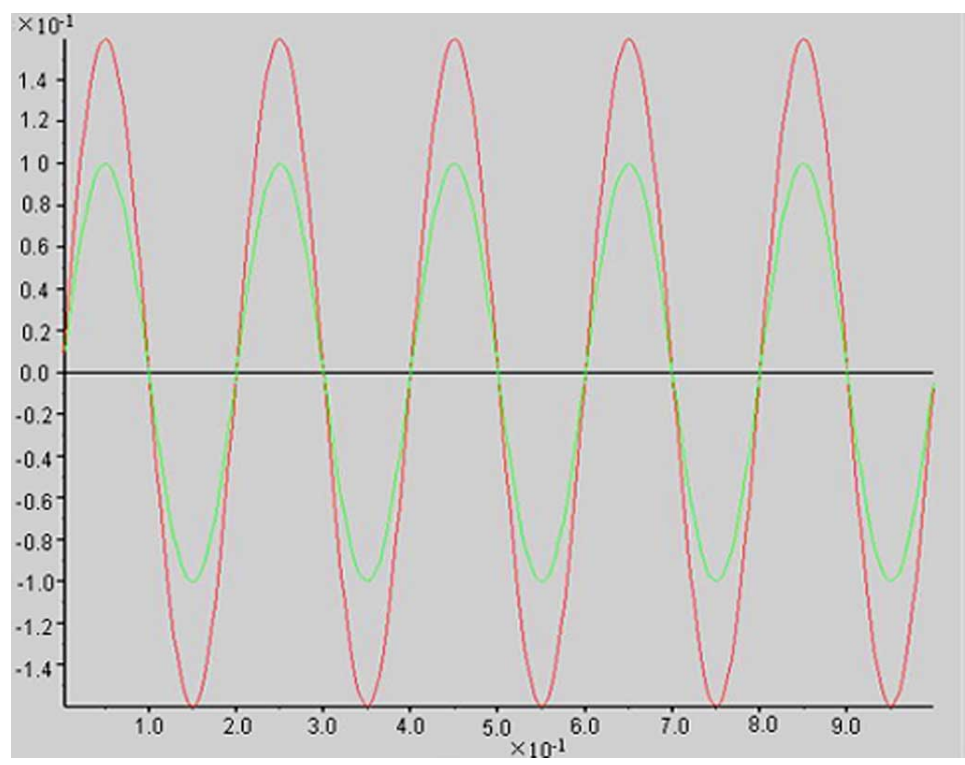

Fig. (1). The time series of loadings.

(The red line denotes the load on the surface of the soil layer, the green denotes the load inner the soil layer.).

Table 1. Comparison of the Numerical and Experimental Settlements

\begin{tabular}{|c|c|c|}
\hline \multirow{2}{*}{ The Distances from Loadings Side } & \multicolumn{2}{|c|}{ The Settlement on the Surface of the Soil Layer / the Settlement on the Surface of the soil on the Load Side } \\
\cline { 2 - 3 } & Centrifuge Experimental Results & Numerical Results \\
\hline \hline$x=0$ & 1.0 & 1.0 \\
\hline$x=1.3 h$ & 0.49 & 0.43 \\
\hline$x=3.0 h$ & 0 & 0 \\
\hline
\end{tabular}

Where: $h$ - bucket's height

modeled only by the coulomb friction cell on the interface by Li [12]. Usually, this method is reliable in static simulation, but the coulomb friction cell is not fitful in dynamical simulation. According to the centrifugal experimental results under dynamic loadings, the bucket and the soil inner the bucket forms a complete stiff unit. Therefore, a simplified numerical model is proposed based on the following assumptions: 1) the soil layer is assumed to be finite in deep direction and semi-infinite in horizontal direction; 2) the bottom boundary is impermeable and vertically end-fixed; 3) the surface of the soil layer is free.

The horizontal damage and the bearing capacity of bucket foundation can be described by p-y curves. The stiffness coefficient is adopted as the sand layer's elastic modulus $E_{0}$, with which the horizontal bearing capacity of bucket foundation when the sand layer have not liquefied can be determined. The resistance in different depth on the right side of bucket is equivalent to different spring stiffness coefficient which is taken as $\left(1-F_{l}\right) E_{0}\left(F_{l}\right.$ is the liquefaction degree) for liquefied sand layer. Define the degradation degree as the ratio of the capacity of bucket foundation in liquefied sand layer and the bearing capacity of bucket foundation in no-liquefied sand layer. In this way, the stress and strain of the saturated sand layer is mainly investigated under dynamic loadings. Firstly, the initial earth stress is computed under side-confined conditions. Secondly, the loading is applied on at the left side (loadings side). The nonreflecting conditions are adopted at the right side. In order to model the interaction between the bucket and the soil layer, the dynamic loading is applied as a sine wave and the amplitude of loading decreases gradually from the surface to the bottom. The loading data in computation are adopted from the centrifugal experimental results [10]. The frequency of dynamic loadings is $1.0 \mathrm{~Hz}$.

\section{Determination of the Parameters}

During the simulation, the soil layer is considered to obey the Mohr-Coulomb model, the pore water is thought to be isotropic elastic. According to the physical and tri-axial compressive testing data [9], the parameters of the sand layer are as follows: elastic modulus $2.6 \times 10^{8} \mathrm{~Pa}$, Poisson's ratio 0.3 , internal friction angle $36.5^{\circ}$, density $1600 \mathrm{~kg} / \mathrm{m}^{3}$.

\section{Reliability of the Numerical Model}

The numerical results of settlements at the surface of sand layer are compared with the centrifugal experimental results after the dynamic loading is applied for more than 20 hours (Table 1). It is shown that the numerical results and the experimental results are agreement well with each other. 


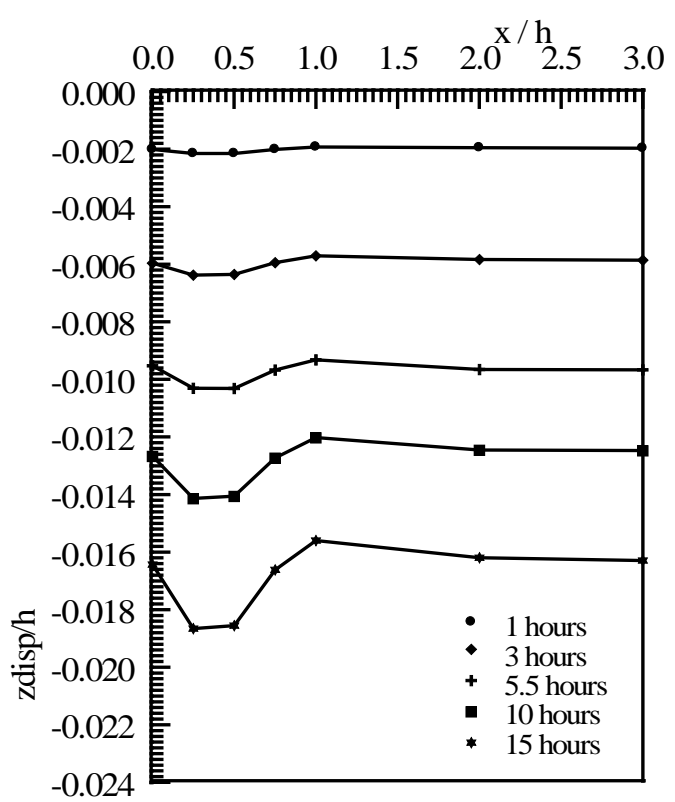

(a) $z=h$

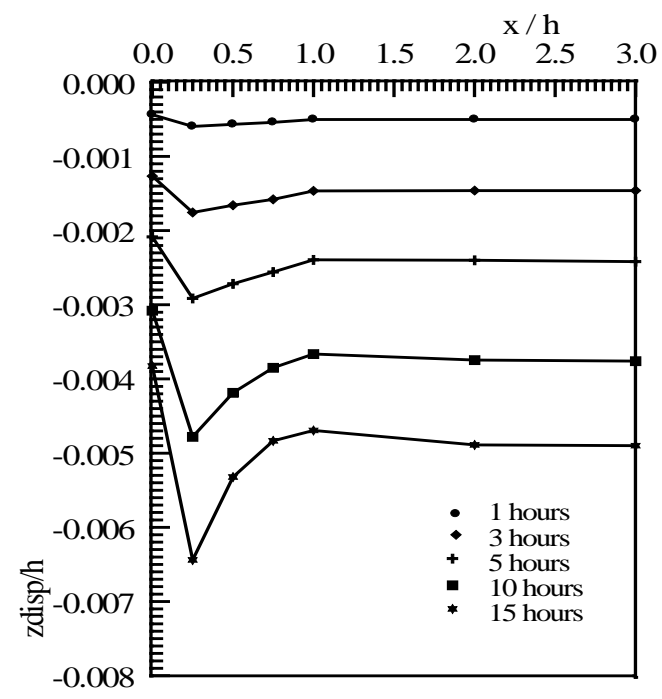

(b) $z=0.2 h$

Fig. (2). The distribution of settlement on the surface of sand layer with time.

\section{THE SETTLEMENTS NEAR THE SAND LAYER'S SURFACE AND BOTTOM UNDER DYNAMIC LOAD- INGS}

\section{Distribution of the Settlement in Horizontal Direction}

The distribution of the settlements near the sand-layer's surface and bottom under dynamic loadings in horizontal direction is shown in Fig. (2). Fig. 2(a) and (b) show the settlements when the loadings is applied for 1, 3, 5.5, 10 and 15 hours. From Fig. 2(a), we can see that the settlements on the surface of the sand layer reach the maximum in $0.25 h \sim 0.5 h$ away from the boundary, and then decreases gradually in the distance of $0.5 h \sim 1.0 h$. In the range of $x>h$ away from the boundary, the settlements keep a small value. The sediment zone looks like a "pan" in the range of $x<h$ at the surface of the sand layer. The "pan" zone is more and more obvious, and the settlements is more and more big inner the "pan" zone with time until the settlements arrives at the maximum. From Fig. 2(b), we can see that the settlement near the bottom is obvious in the distance of $x<h$. In the range of $x>h$, the settlements keep a small value. Compared with that near the surface of the sand layer, the settlement zone looks like a triangle, the maximum settlement is located at $x=0.25 h$.

Development of the Maximum Settlements near the Surface and the Bottom of Sand Layer

Fig. (3) shows the development of the maximum settlements near the surface and bottom of the sand layer at the location of $0.25 h$. It is shown that the settlements increases fast at the beginning. The settlement on the surface is 3 times as much as that at the bottom when the loading is applied for 5 hours.

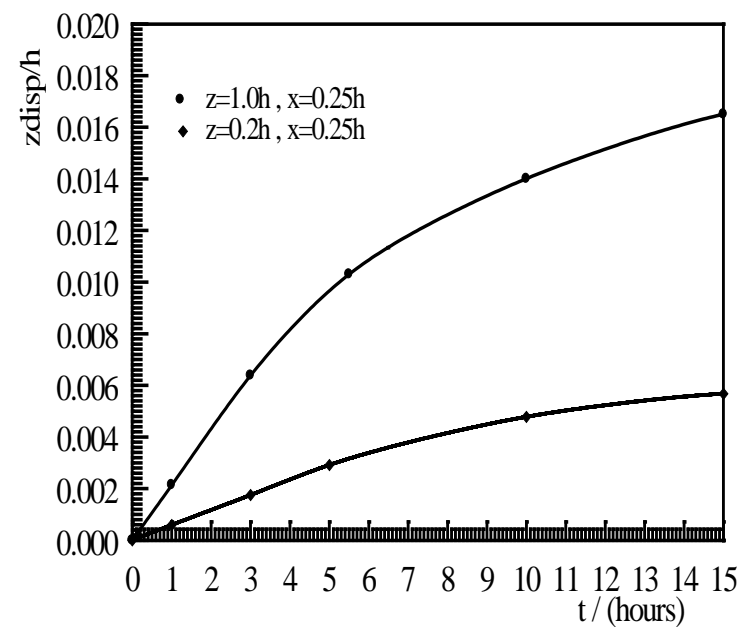

Fig. (3). Development of settlement of sand layer at the bottom and on the surface.

\section{HORIZONTAL DISPLACEMENTS OF THE SAND LAYER UNDER DYNAMIC LOADINGS}

\section{Distribution of the Horizontal Displacement}

Fig. (4) shows the distribution of the horizontal displacement of the sand layer when the loadings are applied for 5 hours. It can be seen that the displacements of the sand layer decreases gradually in horizontal direction. The distribution of horizontal displacements is so small that it can be neglected if the distance away the loadings side is over one times of the bucket's height $(x>h)$. Accordingly, it can be considered that the maximum horizontal displacement is at the loadings side $(x=0)$, and the minimum is at the location 1.0 times of the bucket's height $(x=h)$ away the loading side.

\section{Distribution of the Horizontal Displacement Along Depth}

Fig. (5) shows the distribution of horizontal displacements of the sand layer along depth on the loading side without the effects of the bucket's height, when the dynamic loadings is applied for 1,3,5,10 and 15 hours respectively. It can be seen that the horizontal displacements of the sand 


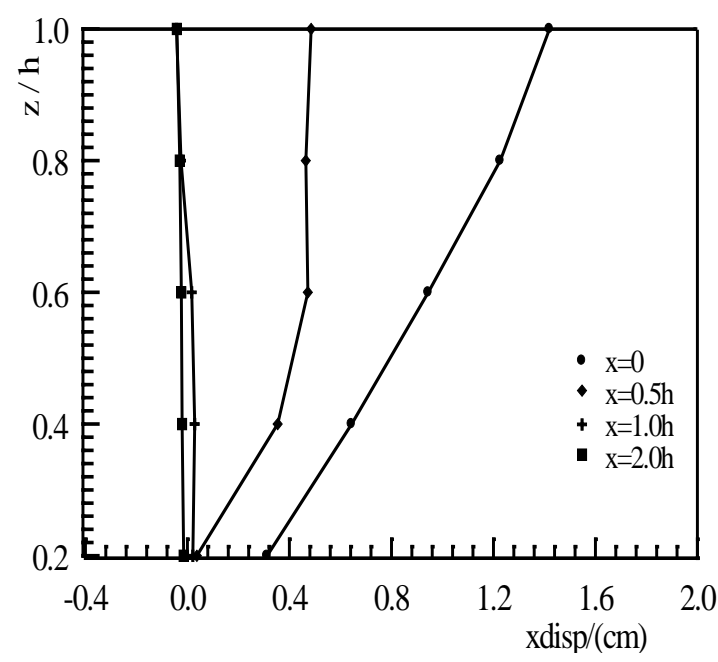

Fig. (4). The horizontal displacement at different distances from the loadings side.

layer decrease gradually along depth from the surface to the bottom. The maximum is on the surface and the minimum is at the bottom. The displacements increase also gradually with time.

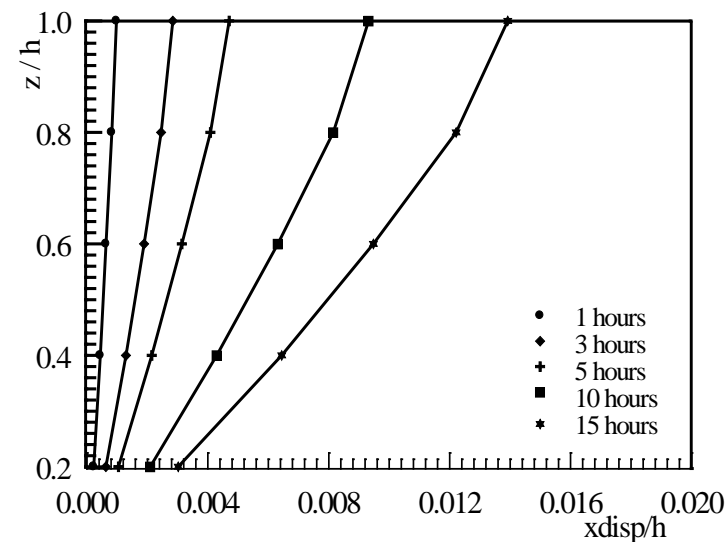

Fig. (5). Distribution of horizontal displacement along depth at different time.

\section{Development of the Horizontal Displacements with Time}

Fig. (6) shows the development of horizontal displacements with time. It is shown that the horizontal displacements increase fast at first and then arrive at a stable value. At the location $2 h$ away from the loading side, the horizontal displacements are so small that it can be neglected. When the dynamic loading is applied for 5 hours, the horizontal displacement of the sand layer at the location of $2 h$ is $1 / 30$ as much as that at the loadings side.

\section{EFFECTS OF THE LOADING CHARACTERISTICS ON THE VERTICAL AND HORIZONTAL DIS- PLACEMENTS}

\section{Effects of the Loading Characteristics on Vertical Dis-} placements

Fig. (7) shows the effects of loading characteristics on the settlements on the surface of the sand layer. It is shown that the settlements in horizontal direction on the surface

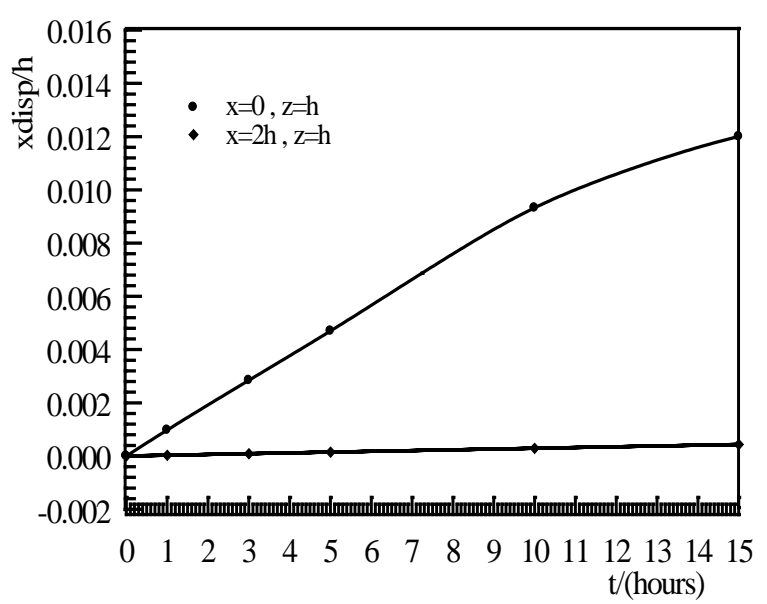

Fig. (6). Horizontal displacement versus time.

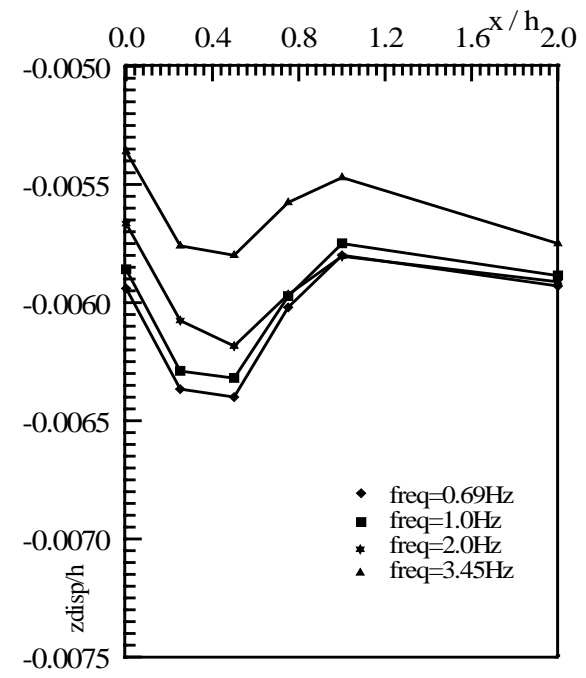

(a) loading frequency

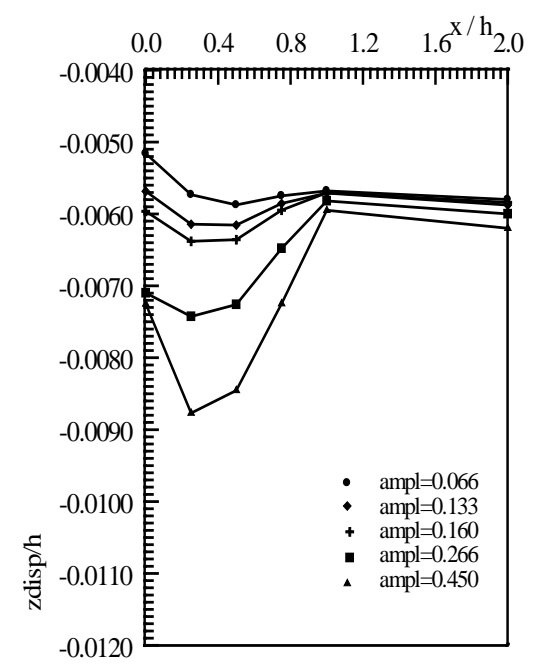

(b) loading amplitude

Fig. (7). Effects of loading frequency and amplitude on the vertical displacement.

changes with the frequency and amplitude of dynamic loadings. Fig. (8) shows that the effects of loading characteristics 
on the maximum displacement on the surface of the sand layer (the position is $x=0.25 h, z=h$ ) when the loading is lasted for 5 hours. It can be seen that the drainage velocity reduces with the frequency increases, so the settlement on the surface of the sand layer increases; Fig. 8(a) shows that the vertical displacement on the surface of the sand layer increases with the decrease of the loading amplitude. Fig. $\mathbf{8}(\mathbf{b})$ shows that vertical displacements on the surface of the sand layer increases with the increase of loading amplitudes.

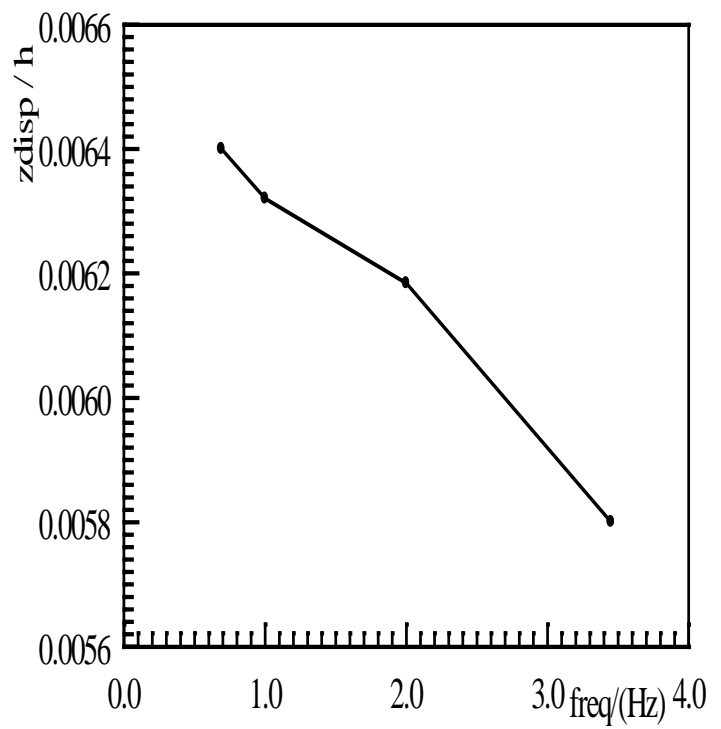

(a) effects of loadings frequency

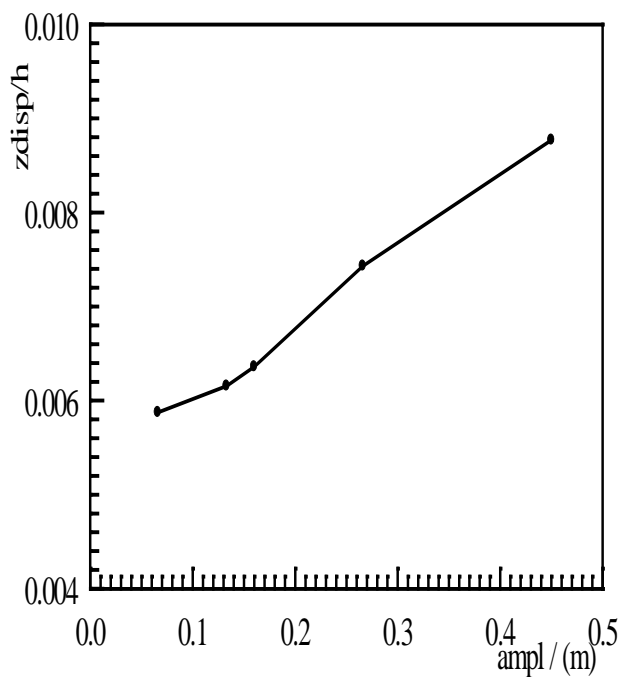

(b) effects of loadings amplitude

Fig. (8). The maximum settlement on the surface of sand layer versus loadings frequency and amplitude.

\section{Effects of the Loading Characteristics on the Horizontal Displacements}

Fig. (9) shows the distribution of horizontal displacement of the sand layer along depth at the loading side. It is shown that the horizontal displacements along depth decreases with the increase of loading frequencies, while they increase with the increase of loading amplitudes. Fig.10 shows the effects of the loadings characteristics on the maximum horizontal displacement at the position $x=0$ and $z=h$ when the dynamic loading is applied for 5 hours. It can be seen that the maximum horizontal displacements increases with the decrease of loading frequencies and the increase of loading amplitudes.

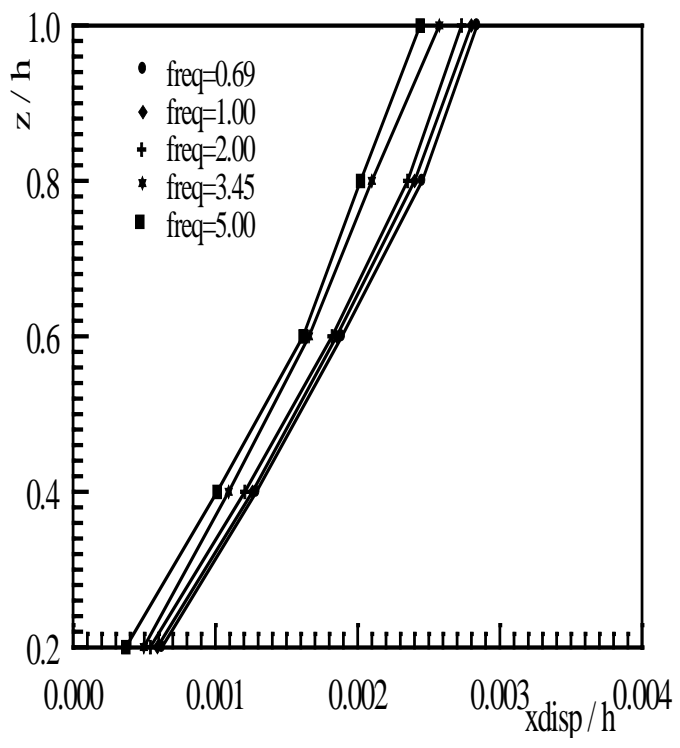

(a) effects of loadings frequency

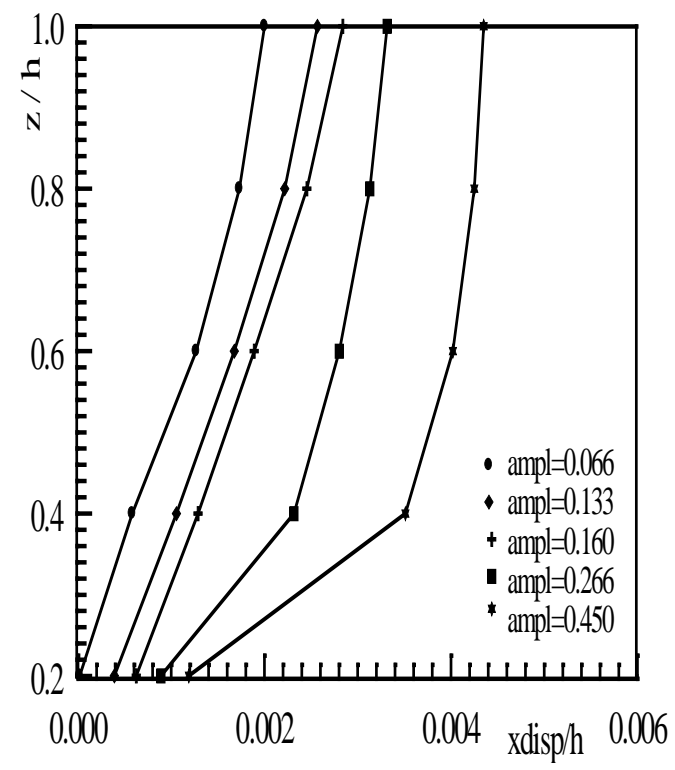

(b) effects of loadings amplitude

Fig. (9). Effects of loading frequency and amplitude on the distribution of horizontal displacement.

\section{EFFECT OF THE SOIL LAYER'S PARAMETERS ON THE VERTICAL AND THE HORIZONTAL DIS- PLACEMENTS}

The development of the displacement of the sand layer changes with the difference of elastic modulus of the sand 


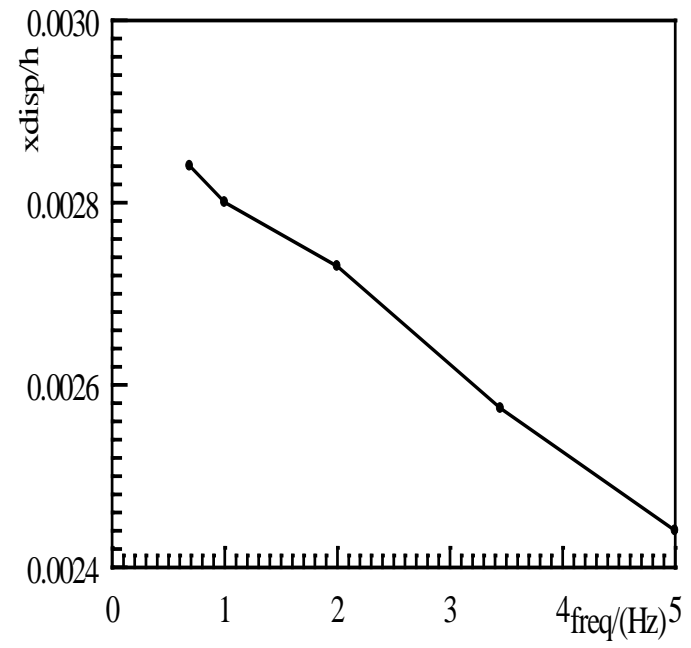

(a) effects of loading frequency

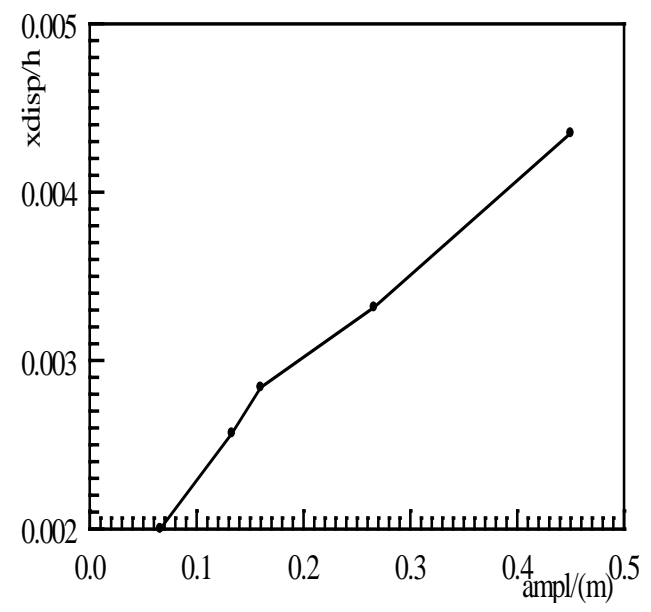

(b) effects of loading amplitude

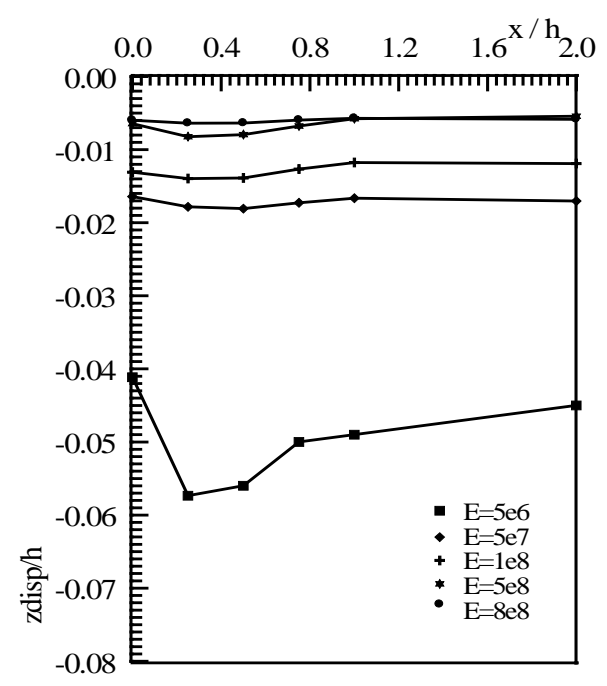

(a) vertical displacement

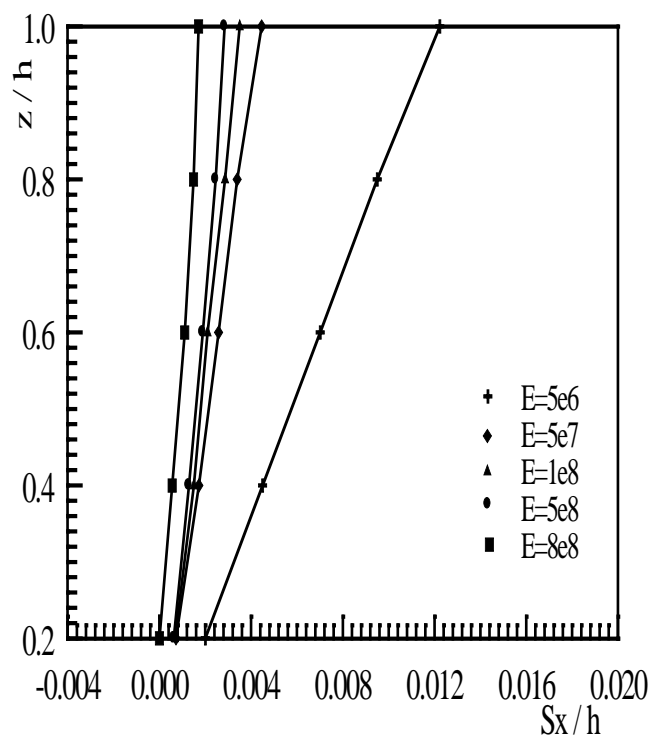

(b) Horizontal displacement

Fig. (11). Development of displacements of sand layer with elastic modulus.

The reliability of this model is validated by comparison the numerical results with the centrifugal experimental results. The effects of main factors on the liquefaction of sand layer are analyzed. It is shown that the deformation of sand layer increases with the decrease of the loading frequencies and the modulus of the skeleton and with the increase of the loading amplitude. The effects of loading amplitudes on the deformation of sand layer are more obvious than that of loading frequencies. The effects of the soil skeleton's modulus on the displacements of sand layer are serious, for an instance, the displacements decrease about $1 / 3$ when the modulus of soil skeleton increases 10 times. 


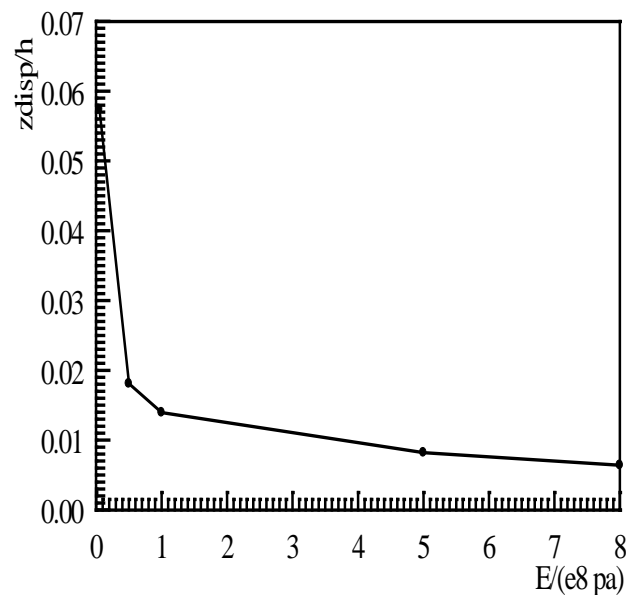

(a) Vertical displacement

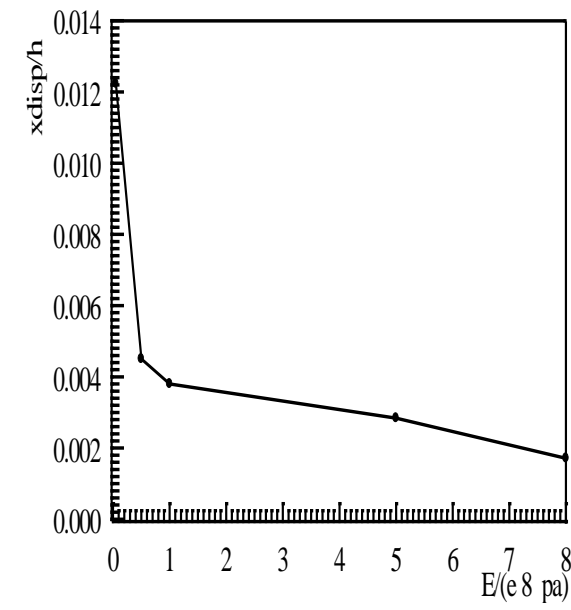

(b) Horizontal displacement

Fig. (12). Settlement and horizontal displacement of sand layer versus elastic modulus.

\section{ACKNOWLEDGEMENT}

This study is supported by the Key Program of Chinese National Offshore Oil Co. and Chinese Academy of Sciences (KJCX2-SW-L03-01).

\section{REFERENCES}

[1] W. F. III Marcuson, R. W. Cunny and M. Chum, "Definition of terms related to liquefaction," Journal of Geotechnical Engineering Division, ASCE, Vol. 104, No. 9, pp. 1197-1120, September 1978.

[2] S. Yasuda, N. H. Kiku and Y. Uchida, "The mechanism and a simplified procedure for the analysis of permanent ground displacement due to liquefaction," Soils and Foundations, Vol. 32, No. 1, pp. 149-160, March 1992.

[3] Y. Shamoto, M. Sato and J. M. Zhang, "Simplified estimation of earthquake-induced settlements in saturated sand deposits," Soils and Foundations, Vol. 36, No. 1, pp. 39-50, March 1996.

[4] J. M. Zhang and G. Wang, "Pile-soil dynamic interaction analysis considering large post-liquefaction ground deformation," Journal of Tsinghua University (Science and Technology), Vol. 44, No. 3, pp. 573-577, March 2004.

[5] J. M. Zhang and G. Wang, "Mechanism of large post-liquefaction deformation in saturated sand,"Chinese Journal of Geotechnical Engineering, Vol. 28, No. 7, pp. 835-840, July 2006.

[6] H. L. Liu, Y. D. Zhou and Y. F. Gao, "Study on the behavior of large ground displacement of sand due to seismic liquefaction," Chinese Journal of Geotechnical Engineering, Vol. 24, No. 2, pp. 142-146, February 2002.

[7] Y. F. Gao, H. L. Liu and W. Zhu, "Advances in: large ground displacement induced by seismic liquefaction," Rock and Soil Me chanics, Vol. 21, No. 3, pp, 550-555, March 2000.

[8] J. H. Lin and Q. X. Huang, "Calculation and analysis of large ground displacement induced by seismic liquefaction," Journal of Huaqiao University (Natural Science), Vol. 25, No. 2, pp. 21-26, February 2004.

[9] X. B. Lu, Z. M. Zheng and J. L. Zhang, "Progress in: the study on the bucket foundation of offshore platform," Advances in Mechanics, Vol. 33, No. 1, pp. 27-40, January 2003.

[10] X. B. Lu and P. Cui, "The liquefaction and displacement of highly saturated sand under water pressure oscillation," Ocean Engineer ing, Vol. 31, No. 7, pp. 795-811, February 2004.

[11] Y. H. Wang, X. B. Lu and S. Y. Wang, "The response of bucket foundation under horizontal dynamic loading," Ocean Engineering, Vol. 33, No. 7, pp. 964-973, July 2006.

[12] C. Li, J. H. Wang and Z. W. Liu, "Cyclic bearing capacity of single bucket foundation on soft clay strata," Chinese Journal of Geotechnical Engineering, Vol. 27, No. 9, pp. 1040-1044, September 2005.

(C) Li et al.; Licensee Bentham Open.

This is an open access article licensed under the terms of the Creative Commons Attribution Non-Commercial License (http://creativecommons.org/licenses/by-nc/3.0/) which permits unrestricted, non-commercial use, distribution and reproduction in any medium, provided the work is properly cited. 